\title{
CELEBRAR OU LAMENTAR: RILKE
}

\author{
Vinícius Honesko \\ Doutorando em Literatura - UFSC
}

\section{RESUMO}

O presente ensaio aborda a poesia de Rainer Marie Rilke para além das leituras que o definem como poeta hermético ou até mesmo místico. Para tanto, procura expor como o processo poético rilkeano se mostra como uma tentativa de capturar o vazio constitutivo da palavra. Aponta como Rilke declara uma propriedade da morte como parte necessária do processo de captura. Tenta mostrar também como o projeto do poeta, aqui denominado esotérico, esbarra num limite: justamente a declaração de propriedade da morte no momento mesmo em que o poeta pretende tornar-se uma coisa, um objeto. Assim, demonstra como Rilke se dá conta do vazio que constitui o humano sem, contudo, avançar nessa idéia. Conclui que a poesia de Rilke se torna um lamento pela perda da propriedade da morte e até mesmo do humano.

\section{PALAVRAS-CHAVE}

Rilke; Vazio; Propriedade da morte; Esotérico; Lamento.

\section{TO CELEBRATE OR TO REGRET: RILKE}

\begin{abstract}
The present essay approaches the poetry of Rainer Marie Rilke beyond the readings which define him as an hermetic or even mystic poet. It tries to expose how Rilke's poetic process seems to be an attempt to grasp the constitutive emptiness of the word. It shows how Rilke declares a propriety of death as necessary part of the process of grasping. It also tries to show how the poet's project, here called esoteric, bumps up against a limit: exactly the declaration of a propriety of death in the same moment in which the poet intends to become a thing, an object. Therefore, it demonstrates how Rilke realizes the emptiness that constitutes the human without, however, go on with this idea. It concludes that the poetry of Rilke becomes a regret for the loss of the propriety of death and even of the human.
\end{abstract}

\section{KEY-WORDS}

Rilke; Emptiness; Propriety of death; Esoteric; Regret. 
Na poesia Glosas sobre um Exxtase de Alta Contemplação, de João da Cruz, o

frei faz experiência de um misticismo sublime:

Entrei onde não soube

E quedei-me não sabendo

Toda a ciência transcendendo

1. Eu não soube onde entrava

Porém, quando ali me vi,

Sem saber onde estava,

Grandes coisas entendi;

Não direi o que senti,

Que me quedei não sabendo,

Toda a ciência transcendendo.

2. De paz e de piedade

Era a ciência perfeita,

Em profunda soledade

Entendida (via reta);

Era coisa tão secreta,

Que fiquei como gemendo,

Toda ciência transcendendo.

3. Estava tão embevecido,

Tão absorto e alheado,

Que se quedou meu sentido

De todo o sentir privado,

E o espírito dotado

De um entender não entendendo,

Toda a ciência transcendendo.

4. O que ali chega deveras

De si mesmo desfalece;

Quanto sabia primeiro

Muito baixo lhe parece,

E seu saber tanto cresce,

Que se queda não sabendo,

Toda a ciência transcendendo.

5. Quanto mais alto se sobe,

Tanto menos se entendia,

Como a nuvem tenebrosa

Que na noite esclarecia;

Por isso quem a sabia

fica sempre não sabendo,

Toda a ciência transcendendo.

6. Este saber não sabendo

É de tão alto poder,

Que os sábios discorrendo

Jamais o podem vencer,

Que não chega o seu saber

A não entender entendendo,

Toda a ciência transcendendo.

7. E é de tão alta excelência

Aquele sumo saber,

Anuário de Literatura, ISSNe: 2175-7917, vol. 14, n. 1, 2009, p. 116 
Que não há arte ou ciência

Que o possam apreender;

Quem se soubera vencer

Com um não saber sabendo,

Irá sempre transcendendo.

8. E se o quiserdes ouvir, Consiste esta suma ciência

Em um subido sentir

Da divinal Essência;

É obra da sua clemência

Fazer quedar não entendendo,

Toda a ciência transcendendo (SÃO JOÃO DA CRUZ, 1996, pp. 38-40).

Sem saber onde entra, não pode dizer o que sente, pois não o sabe. Mantém-se gemendo, entendendo não entendendo, num saber que não importa o quanto cresça continua sem saber. Contra esse saber - o sumo saber; o saber abismal, indizível nenhum discurso pode se elevar (não se pode vencê-lo); nem aquele da ciência, nem o da arte conseguem apreendê-lo, e quem nele permanece "com um não saber sabendo / Irá sempre transcendendo."

As palavras místicas de João da Cruz dão mostra de uma experiência indizível - impronunciável - que é o encontro com o Deus Sublime. Fundindo-se na profunda essência desse indizível, João parece viver o conhecimento mais profundo, que transcende toda ciência, que supera toda forma de dizer, que aponta para o fundo vazio e inapreensível do mistério, do inefável. A impossibilidade de dizer essa experiência aponta para um abismo silencioso, o lugar do silêncio, para o que os gnósticos da antiguidade tardia chamavam Sigé.

João da Cruz canta em poesia tal lugar onde chega em seu êxtase sem, entretanto, poder dizer que lugar era esse. Não pode dizer onde esteve. Ele pode apenas indicar o lugar sem poder dizê-lo. Mas o que significa tal impossibilidade? Por que pode João da Cruz indicar o lugar em que esteve sem, no entanto, significá-lo - "Entrei onde não soube / E quedei-me não sabendo"? A mística aponta sempre para um lugar que, em si mesmo, permanece indizível. O que esse indizível representa é um problema que deve ser esclarecido.

De fato, a poesia do frei marca abruptamente um espaço no qual o eu-indivíduo João da Cruz se dissolve totalmente no inefável - é uma copulatio misteriosa, que faz com que seu espírito, seu ser - sempre em sentido metafísico -, se una em comunhão misteriosa com o Eterno. É interessante anotar que o próprio João da Cruz, em um de seus escritos catequéticos, Subida ao Monte Castelo, alerta que qualquer êxtase 
experimentado empiricamente pelos sentidos é "fonte de freqüentes erros e numerosos perigos", e continua, "há tanta diferença entre a sensibilidade e a razão como entre o corpo e a alma, e, na realidade, o sentido corporal é tão ignorante das coisas espirituais como um jumento o é das coisas racionais, e mais ainda" (Idem. p. 217). Todos esses alertas em relação às percepções naturais - que João vai repetir no decorrer do texto nos fazem perceber uma sutileza elementar de uma situação de comunhão mística: a ascese em relação ao mundo sensível, a desconsideração em relação aos objetos que nos cercam, o hermetismo absoluto do ser em relação ao ente em que ele se dá.

Que a poesia de Rilke possa muitas vezes ser encarada como "hermética", "mística" e "obscurantista" é já uma pista da dificuldade com a qual o leitor se depara no seu confronto com os temas rilkeanos. Anjos, feras, coisas, morte, enigmas, enfim, todo o cabedal onomástico presente nos textos do poeta alemão parecem circunscrevem uma lógica de cunho místico por excelência. No entanto, por mais que tais impressões possam ser retidas, talvez não seja disso que se trate no pensamento de Rilke pensamento porque a poesia rilkeana transmuta-se, inadvertidamente, em pensamento. ${ }^{1}$ Sua tentativa parece ser, ao contrário, a - incrivelmente paradoxal - de uma apreensão nostálgica de uma animalidade perdida, tal como ele lamenta na oitava Elegia de Duíno:

Com todos os seus olhos, a criatura vê o Aberto. Nosso olhar, porém, foi revertido e como armadilha se oculta em torno do livre caminho.

O que está além, pressentimos apenas na expressão do animal; pois desde a infância desviamos o olhar para trás e o espaço livre perdemos, ah, esse espaço profundo que há na face do animal. Isento de morte. Nós só vemos morte. O animal espontâneo ultrapassou seu fim; diante de si tem apenas Deus e quando se move é para a eternidade, como correm as fontes (RILKE, 2001, p. 73).

Nós, os homens, só vemos a morte, enquanto o animal vê o espaço livre, um espaço profundo isento de morte. $\mathrm{O}$ além do fim do animal, sua integração visual com Deus, seu não-se-lançar numa temporalidade especificamente sua, parece ser a superação profunda do estatuto ontológico próprio ao homem; ou seja, ao homem, na relação enquanto ser com seu ente (relação ôntico-ontológica), não é possível ser nem

\footnotetext{
${ }^{1}$ Noto a reversão à fórmula de Wittgenstein (“a filosofia só se pode poetar”) efetuada por Agamben: “A poesia só pode filosofar.”
} 
ver além, mas tão somente gemer à espera da redenção que se manifestaria apenas na propriedade da morte. Uma morte própria, autêntica, reveladora da obra humana. Ou seja, como sugere Blanchot nas suas leituras de Rilke, "devemos ser os artífices e os poetas de nossa morte" (BLANCHOT, 1987, p. 123). Assim, Rilke, diante da modernidade que se lhe abria abruptamente, parece hesitar diante da impessoalidade e expropriação da vida - e da morte - na metrópole, clamando por uma propriedade da morte quando esta já não podia ser senão serialidade, aviltamento ou, ainda, apenas falecimento - lembremos que ele morou em diversos lugares da Europa e que, em Paris, a cidade que se tornou mercadoria desde a Exposição Universal de 1889 (AGAMBEN, 2007a, p. 72), é que ele escreve Die Aufzeichnungen des Malte Laurids Brigge, texto em que expressa com mais afinco seus pensamentos sobre a morte; e é também Paris, segundo sua carta de 16 de julho de 1903 para Franz Xaver Kappus, o lugar “onde tudo ressoa e esmorece de outro modo, devido ao excessivo barulho que faz as coisas estremecerem" (RILKE, 2003, p. 41-42).

É de toda forma importante lembrar as palavras de Adorno em face dessa concepção de uma autenticidade e de uma propriedade da morte em Rilke. Assim escreve o frankfurtiano no fragmento 148, denominado Matadouro, de Mínima Moralia (livro cujo subtítulo, Reflexões a partir da vida danificada, já esboça a tonalidade dos ataques adornianos àqueles que ainda parecem crer numa dignidade da vida humana pós-totalitarismos ${ }^{2}$ ):

$\mathrm{O}$ que os nacional-socialistas perpetraram em milhões de pessoas, a inspeção dos vivos como se estivessem mortos, em seguida a produção em massa e o barateamento da morte, projetava por antecipação sua sombra sobre aqueles que para rir inspiram-se em cadáveres. O que é decisivo é que a destruição biológica foi acolhida conscientemente na vontade social. Só uma humanidade à qual a morte tornou-se tão indiferente quanto seus membros, uma humanidade que morreu para si mesma, pode infligi-la administrativamente a incontáveis indivíduos. A prece de Rilke pela morte pessoal é a lamentável tentativa de ocultar o fato de que os homens, nos dias de hoje, não fazem mais do que pifar (ADORNO, 1992, p. 204).

Adorno enxerga no gesto rilkeano a tentativa lamentável de regresso à um paraíso perdido, a um espaço no qual a morte entronizava um posto capaz de dar ao homem seu caráter de humano; isto é, que somente como ser-para-a-morte o humano

${ }^{2}$ Lembremos que as três partes que compõem o livro foram escritas respectivamente em 1944, 1945 e 1946-7, isto é, justamente nos anos finais e imediatamente posteriores ao maior aniquilamento que a humanidade jamais teria visto. 
poder-se-ia abrir à sua propriedade, algo que, na modernidade já está fadado ao fracasso (obviamente que podemos ler aqui a crítica ferrenha de Adorno a Heidegger, autor que, sem dúvidas, não constava dentre aqueles de sua predileção). Porém, essa dignidade da morte que o pensamento rilkeano parece almejar, ainda que ele estivesse ciente do paradoxo fantasmagórico no qual adentrara ao fazer tal requerimento, é passível também de ser analisada sob um viés diverso, isto é, sob um prisma imagético-jurídico que perpassa uma recente teorização do direito contemporâneo.

Um instituto do Direito Romano nos dizia: Dignitas non moritur - A dignidade não morre jamais. É a partir desse princípio que se constrói toda uma doutrina contemporânea - frise-se que seu locus principal se dá na Alemanha pós-nazista (talvez como voto penitente) - a respeito da dignidade da pessoal humana. É interessante anotar que a dignidade de que falavam os romanos jamais se dava como algo implícito à vida pessoal; não se pode dizer que em Roma havia uma aposta num princípio humanístico que pudesse instituir uma espécie de carga de dignidade com a qual toda e qualquer pessoa nascesse. Ao contrário, a dignidade dizia respeito a autoridade de determinados cargos públicos. Um exemplo importante a partir do qual podemos tirar algumas conclusões está no momento da morte do imperador. No seu rito funerário era possível vislumbrar todo o resplandecer autóctone da dignidade em face de seu portador. Como bem relata Ernst Kantorowicz em seu Os dois corpos do rei, ${ }^{3}$ o rito funerário dos imperadores romanos tratava de modelar uma efígie (imago) do corpo do morto, esta que era tratada como um moribundo no leito de morte, mesmo depois de falecido o imperador. Ou seja, de maneira suplementar a imagem do imperador era cunhada de modo a poder levar à apoteose a vida digna (a vida sacra, nos dizeres de Agamben) do imperador, enquanto seu corpo natural já havia sido sepultado, como se a dignidade fosse um plus de vida à própria vida (uma intransigência imortal), ou ainda algo que sobrevivesse à morte. Essa noção de dignidade - tão prenhe de sentido em qualquer discurso ético-moralista na contemporaneidade, este que pretende estender a todos e quase a tudo uma instância íntima de dignidade - já nasce sob o signo da divisão no próprio corpo de seu portador; por assim dizer, este possui em si duas vidas, uma digna (uma vida do ser: imortal e gloriosa) e outra dejetual (uma vida do ente: mortal e

3 Kantorowicz analisa essa questão do Digntas non moritur no sétimo capítulo do seu livro $C f$. KANTOROWICZ, Ernst. Os Dois Corpos do Rei. Um estudo sobre teologia política medieval. São Paulo: Companhia das Letras, 1998. Tradução: Cid Knipel Moreira. pp. 233-272. De fato, o estudo de Kantorowicz diz respeito não aos funerais romanos, mas sim ao lit d'honneur da Idade Média. 
natural); lendo-se de outra maneira, uma vida efetivamente humana e outra inumana (animalesca).

A dignidade de uma vida humana, resplandecente na propriedade da morte que libera, por assim dizer, uma dignidade em estado puro enquanto produz o cadáver como dejeto desta -, pode ser colhida como o fruto de um humanismo que pretende dissociar no próprio seio do homem (ainda vivo) uma inumanidade lateral, cuja insólita figura pode ser equacionada naquilo que Agamben denomina de homo sacer - o matável, porém insacrificável (AGAMBEN, 2002). ${ }^{4}$ Não podemos perder de vista, no entanto, que tal dissociação não passa do sonho de uma existência pura, de um ser puro, um ser glorioso (aliás, que o programa político-existencial da humanidade tenha se fundado numa exclusão do corpo-dejeto da esfera da polis numa tentativa inapreensível de fundação de uma comunidade estruturada de modo coeso num Povo, numa Nação, não pode ser aqui deixado de lado).

O espaço próprio da modernidade, ou seja, a Metrópole - que tanto perturbava Rilke - é justamente o ponto em que o aviltamento da morte se dá na sua forma mais significativa. Esse lugar, onde os homens se reúnem em números jamais antes provados, é também o ponto de maior desconexão entre os homens, é o não-lugar dos encontros humanos. Como lembra o coletivo impessoal Tiqqun:

O homem faz na metrópole a prova de sua condição negativa, puramente. A finitude, a solidão e a exposição, que são três coordenadas fundamentais dessa condição, tecem o cenário da existência de cada um no seio da grande cidade. Não o cenário fixo, mas o cenário movente, o cenário combinatório da grande cidade, pelo qual todo mundo suporta a fedentina paralisada de seus não-lugares (TIQQUN, 2000, p. 55). ${ }^{5}$

$\mathrm{O}$ fato de que, em várias passagens de suas cartas, a recomendação primordial que Rilke dá a F. X. Kappus seja a solidão parece demonstrar a paradoxal situação do poeta diante da condição moderna da humanidade. E é justamente em rechaço a essa condição que Rilke clama por aquela propriedade da morte. Porém, tal clamor atua em Rilke como um mecanismo de interiorização do objeto perdido, isto é, como a lógica do luto freudiana (AGAMBEN, 1998, p. 67). A insistência de Rilke na propriedade e na

\footnotetext{
${ }^{4}$ Importante anotar as analogias que Agamben faz entre o homo sacer e as figuras imagéticas dos duplos que serviam para suprimirem a falta do cadáver em determinados ritos funerários. Cf. Homo Sacer. O Poder Soberano... pp. 99-110.

5 “' L'homme fait dans la métropole l'épreuve de sa condition négative, purement. La finitude, la solitude et l'exposition, qui sont les trois coordonnées fondamentales de cette condition, tissent le décor de l'existence de chacun au sein de la grande ville. Non pas le décor fixe, mais le décor mouvant, le décor combinatoire de la grande ville, pour quoi tout le monde endure la puanteur glacée de ses non-lieux."
} 
dignidade da morte já não tem nenhum sentido na modernidade; buscar uma morte própria é a condenação que se impinge ao poeta, condenação esta que faz com que ele mostre todo o seu desconforto em face das coisas mais simples e sempre busque - e declare tal busca - as coisas autênticas, que entreteriam um outro tipo de relação com seus portadores. Assim, em carta a Hulewicz, Rilke diz que

a terra não tem outra saída senão tornar-se invisível: em nós, que, com parte de nosso ser, participamos do invisível, temos (pelo menos) cédulas de participação dele e podemos aumentar a nossa posse de invisibilidade durante a nossa permanência aqui - em nós somente pode-se realizar esta íntima e duradoura metamorfose do visível em invisível... $\mathrm{O}$ anjo das Elegias é a criatura na qual aparece já perfeita a transformação do visível no invisível que estamos realizando (RILKE Apud AGAMBEN, 2007a, p. 70).

Que as coisas devam ser agora - no tempo da inautenticidade, da impropriedade - autênticas e próprias, segundo o poeta, não é irrelevante. De fato, como lembra Furio Jesi, Rilke sempre considerou a si mesmo como coisa, justamente "no momento em que se referia à realidade mais sacra do seu eu, isto é, ao seu ser instrumento de uma força que lhe ditava a poesia", continua Jesi, "a sua realidade mais sagrada consistia no ser uma coisa; o seu mundo mais verdadeiro era aquele das coisas, não dos homens" (JESI, 1979). ${ }^{6}$ Rilke transforma o seu eu poético em coisa, em instrumento do desconhecido; isto é, o poeta se abre como um vazio fantasmático dissolvido, deixando-se metamorfosear-se em invisibilidade pura.

Tais gestos rilkeanos escamoteiam a posição do poeta; lançado num movimento vertiginoso ele paradoxalmente elege momentos próprios ao homem (como o caso da morte) e, ao mesmo tempo, abdica de qualquer propriedade ao querer-se apenas coisa, ao querer-se, assim como o animal, também um visionário do Aberto. Assim, continuando a leitura da oitava Elegia:

Ignoramos o que é contemplar um dia, somente um dia o espaço puro, onde, sem cessar, as flores desabrocham. Sempre o mundo, jamais o em-parte-alguma, sem nada: o puro, o inesperado que se respira, que se sabe infinito, sem a avidez do desejo. Uma criança aí se perde, às vezes, em silêncio, mas é despertada. Ou alguém

${ }^{6}$ Artigo encontrado em http://worldlibrary.net/eBooks/Wordtheque/it/AAAARS.TXT: “(...) nel momento in cui si riferiva alla realtà piú sacra del suo io, cioè al suo essere strumento di una forza che gli dettava la poesia. La sua realtà piú sacra consisteva nell'essere una cosa; il suo mondo piú vero era quello delle cose, non degli uomini." 
que morre, nisso se transforma. Pois os que da morte se aproximam não mais a podem ver, fixando o infinito com o grande olhar do animal (RILKE, 2001, p. 75).

Ao homem é interditada a contemplação da pureza de ser que o animal carrega em si como pura possibilidade de existência como coisa, como algo que transcende a morte para permanecer lançado diante do Eterno, diante de Deus. Porém, ainda quando criança ao homem é permitido aproximar-se desse estado (entretanto, alguém - o adulto - sempre irá despertar $a$ e $d a$ criança). Também ao moribundo (o já aviltado em vida, que quase vida não tem, que é pura proximidade com a morte que lhe cega, ou melhor, que lhe abre a visão para além da morte) é liberada a visão do infinito, é superada a fulguração da morte. Para o homem talvez esteja no limiar entre vida e morte a possibilidade de superar sua condição humana e, na poesia de Rilke, reencontrar a visão de animal, re-ver o Aberto.

Essa visão do infinito não seria, porém, assim como a comunhão de João da Cruz com a divindade, uma espécie de misticismo em Rilke? Essa tentativa de anulação do eu-poético como coisa não configura a poesia rilkeana como uma poesia mística? Ainda que tais leituras possam ser feitas, é preciso acentuar que a total invisibilidade e imaterialidade buscadas por Rilke (buscadas, aliás, como certa espécie de fuga da impaciência e da agitação do tempo moderno) podem ser lidas como uma tentativa de sobrevivência (de Nachleben, no sentido de Aby Warburg) como poeta. Este, o poeta, é o devorado pelas coisas que ama, é o ser abandonado pelo tempo e que, paradoxalmente, carrega-se de tempo.

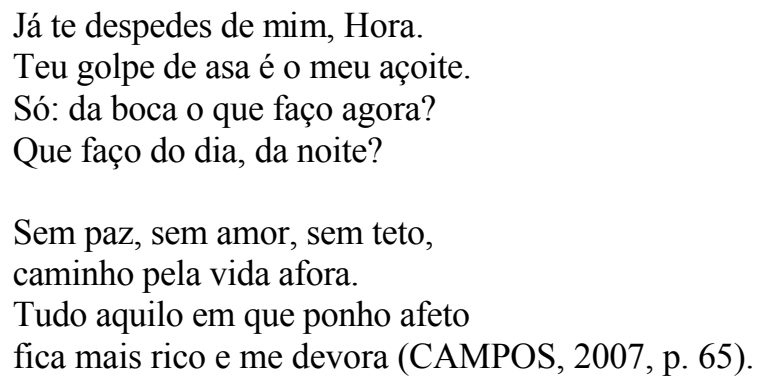

A tentativa de superação do limite da morte (ainda que, lembramos mais uma vez, esse gesto apresente-se contraditoriamente em Rilke, pois ele ainda clama a morte autêntica e a isso as críticas de Adorno e Agamben se mantêm) é aqui, como lê Blanchot, a aproximação da morte como contemporânea da vida (cujo acesso, porém, parece sempre interdito) (BLANCHOT, 1987, p. 131). Nesse sentido, podemos cruzar essas análises da poesia de Rilke com o pensamento de Georg Simmel. Ambos 
participavam dos mesmos círculos intelectuais, cujos freqüentadores eram Bergson, Rodin, Max Weber; além disso, Simmel foi mestre de Lukàcs, Ernst Bloch, isto é, de todo o contexto filosófico e artístico germânico de então (talvez, até Walter Benjamin tenha assistido suas conferências). Em 1909 - isto é, aproximadamente nos mesmos anos em que Rilke escreve os Novos Poemas - Simmel publica um ensaio denominado Metafísica da morte. Interessante notar como Simmel pensa a morte como algo desde sempre internalizado no vivente (no corpo orgânico) e que a este confere forma:

Do mesmo modo que nós não estamos sempre verdadeiramente aí desde o instante do nosso nascimento, mas que há continuamente um pouco de nós nascendo, assim também nós não morremos unicamente no nosso último instante.

Vê-se agora claramente a significação da morte como criadora de forma. Ela não se contenta em limitar a nossa vida, isto é, em lhe dar forma na hora do trespassar; ao contrário, ela é para nossa vida um fator de forma, que dá coloração a todos os seus conteúdos: fixando os limites da vida na totalidade, a morte exerce de antemão uma ação sobre cada um de seus conteúdos e de seus instantes; a qualidade e a forma de cada um deles seriam outras se se pudesse ultrapassar esse limite imanente (SIMMEL, 1988, pp. 171-172).

Vida como forma conferida pela morte, pela dissolução do eu-poeta no caso de Rilke, expõe irrevogavelmente a condição aporética do sujeito falante, isto é, não apenas do sujeito poético, mas também aquela de todo vivente que possui a linguagem (que, lembremos, é a definição aristotélica do homem: zōon logon ekhon). Ou seja, a morte - ou se a lermos como o silêncio que modula os espaço do discurso - vista como um limite interno à vida, e que nesta molda os conteúdos, abre uma tensão no eu-poeta rilkeano: o poeta sabe-se instrumento puro e cego do não-cognoscível que o impinge à escritura (isto é, a morte que o força, que faz com que o poeta sinta a obrigação de escrever ${ }^{8}$ ), mas também se sabe escolhido para participar desse privilégio, ou seja, é

7 "De même que nous ne sommes pas encore vraiment là dès l'instant de notre naissance, mais qu'il y a continuellement un petit peu de nous en train de naître, de même nous ne mourons pas uniquement dans notre dernier instant.

On voit maintenant clairement la signification de la mort comme créatrice de forme. Elle ne se contente pas de limiter notre vie, c'est-à-dire de lui donner forme à l'heure du trepas, au contraire, elle est pour notre vie um facteur de forme, qui donne coloration à tous sés contenus: em fixant lês limites de la vie dans la totalité, la mort exerce d'avance une action sur chacun de ses contenus et de ses instants; la qualité et la forme de chacun d'eux seraient autres s'il pouvait dépasser cette limite immanente."

${ }^{8}$ Como Rilke sugere em carta de 17 de fevereiro de 1903 a F. X. Kappus. RILKE, Rainer. M. Cartas a um Jovem Poeta... p. 26. "O senhor está olhando para fora, e é justamente o que menos deveria fazer neste momento. Ninguém o pode aconselhar ou ajudar - ninguém. Não há senão um caminho. Procure entrar em si mesmo. Investigue o motivo que o manda escrever; examine se estende suas raízes pelos recantos mais profundos de sua alma; confesse a si mesmo: morreria, se lhe fosse vedado escrever? Isto, acima de tudo, pergunte a si mesmo na hora mais tranqüila de sua noite: 'Sou mesmo forçado a 
intencionalmente poeta (AGAMBEN, 2006, p. 100). Aqui podemos ler o dilema que marca a poesia de Rilke: diante dele o poeta não se deixa anular por uma força mística, isto é, que lhe aniquilaria toda vontade; ao contrário, sua posição é, por assim dizer esotérica, que reconhece que sua vontade é insuprimível, mas que, conscientemente, participa de sua própria abolição (Idem).

Poetar, escrever, em suma, falar mostra-se, portanto, como um ato paradoxal. A subjetivação de um eu-poético só pode se constituir sobre a destituição mais absoluta da palavra (assim como a vida, em Simmel, só pode se fundar tendo como seu interior a morte). Em face da proposição aristotélica do animal que possui linguagem, não nos cabe formular quesitos que isolem uma animalidade e uma racionalidade (no sentido do logos da fórmula zōon logon ekhon). De fato, e a poesia de Rilke pode ser vista dessa forma, é acerca do vazio do possuir que o poeta se questiona a todo instante. Como lembra Agamben, ao falar

o indivíduo vivente se apropria da língua unicamente numa expropriação integral, torna-se falante somente sob a condição de um aprofundamento no silêncio. $\mathrm{O}$ modo de ser do eu, o estatuto existencial do vivente-falante é, portanto, uma espécie de glossolalia ontológica, um rumor absolutamente sem substância, no qual o vivente e o falante, a subjetivação e dessubjetivação jamais podem coincidir (AGAMBEN, 1998, p. 120). ${ }^{9}$

O vácuo central que se revela na articulação entre vivente e falante representa assim o vazio nuclear de uma máquina (seja ela mitológica, tal qual pretende Jesi, seja ela antropológica ou ainda lingüística) que se dá para a produção do sujeito do conhecimento. Isto é, o exterior (a morte) é interiorizado como núcleo vazio original da máquina e é a partir dele, desse silêncio - que vemos aqui como a consciência (um saber doloroso sem palavras) -, que a poesia de Rilke pode ser lida: é uma poesia que não tem mais nada a dizer, que procura exprimir apenas o silêncio. Talvez aqui podemos juntar a complexa relação de Rilke com a morte: uma poesia que quer a propriedade da morte justamente por vislumbrar - eis o paradoxo de Rilke - que propriedade, dignidade e autenticidade nenhuma há nesta morte. Em outras palavras, é uma poesia que quer exibir a sua própria dessubjetivação.

escrever?'. Escave dentro de si uma resposta profunda. Se for afirmativa, se puder contestar àquela pergunta severa por um forte e simples 'sou', então construa sua vida de acordo com essa necessidade." 9 “(...) l'individuo vivente si appropria della lingua unicamente in un'espropriazione integrale, diventa parlante solo a patto di sprofondare nel silenzio. Il modo di essere dell'io, lo statuto esistenziale del vivente-parlante è, ciò̀, una sorta di glossolalia ontologica, una diceria assolutamente insostanziale, in cui il vivente e il parlante, la soggettivazione e la desoggettivazione non possono mai coincidere." 
A citação que Furio Jesi recorrentemente fazia dos Sonetos a Orfeu, "Wer sich als Quelle ergießt, den erkennt die Erkennung”, ou seja, "Quem se derrama como fonte, é conhecido do conhecimento", é tomada pelo autor - em um de seus exemplares estudos sobre Károly Kerényi - no ponto em que ele analisa a religio mortis, que para ele era evidente nos "pensamentos secretos" de Ezra Pound (religião da morte esta que poderia ser colocada lado a lado ao fascismo de Pound). Para Jesi essa religião da morte se daria como um tomar parte na conviç̧ão de que com a morte o humano entretém um comportamento “através do qual a morte acederia à 'verdade superior' de ser 'algo e ao mesmo tempo nada"” (JESI, 2001, p. 29). ${ }^{11}$ Isto é,

poesia e mitologia (ou, se quisermos, essência da poesia e da mitologia) sobrevivem na cultura moderna também na medida em que a sua sobrevivência é circunscrita, defesa e alimentada por um "algo e ao mesmo tempo nada" que vale seja como suas definições, seja como horizonte próximo do comportamento com a morte. À sobrevivência da poesia e da mitologia neste presente, e não somente neste, já que não parece ser a primeira vez que isso acontece, parece apropriado, mesmo se talvez não de modo exclusivo, um terreno de cultura que se conserva nutritivo e quente, não obstante os gelos e as esterilizações do agora, graças às qualidades da morte, que são múltiplas e de vários modos de eficácia (Idem.). ${ }^{12}$

Essa tentativa de buscar um conhecimento da morte, de ir às bordas de um conhecimento além do qual só pode estar um derramar-se como fonte, que é ser conhecido pelo conhecimento, é contrapor à morte - enrijecida num 'mito da morte', traduzido aqui no comportamento humano com a morte - um fluir de vida humana, esta que, porém, só pode estar circunscrita por esse "algo e ao mesmo tempo nada" que é a morte.

Desse modo, o "algo e ao mesmo tempo nada" que se funda como o núcleo escondido de uma máquina (mitológica, poetológica ou antropológica) permite a esta seu funcionamento. Somente com um resíduo internalizado - que, porém, é absolutamente vazio - é que todo o mecanismo de formulação de uma propriedade humana pode funcionar. $\mathrm{Ou}$ seja, no núcleo encontramos uma negatividade

${ }^{10}$ Só nos ensaios iniciais de Materiali Mitologici, sobre Kerényi, são três citações.

11 “(...) attraverso il quale la morte accederebbe allá 'verità superiore' d'essere 'qualcosa e insieme nulla',"

12 "Poesia e mitologia (o, se vogliamo, essenza della poesia e della mitologia) sopravvivono nella cultura moderna anche nella misura in cui la loro sopravvivenza è circoscritta, difesa e alimentata da un 'qualcosa e insieme nulla' che vale sia come loro definizione, sia come orizzonte vicino del comportamento con la morte. Alla sopravvivenza della poesia e della mitologia in questo presente, e non solo in questo poiché non pare essere la prima volta che ciò accade, sembra appropriato, anche se forse non in modo exclusivo, un terreno di coltura che si conserva nutritizio e caldo nonostante $i$ geli e le sterilizzazioni dell'ora, grazie alle qualità della morte, che sono molteplici e in vario modo efficaci." 
fundamental, no sentido blanchotiano - a consciência pela qual escapamos ao que é sempre presente mas nos entregamos à representação (BLANCHOT, 1987, p. 131). Recordemos, mais uma vez, aquele supracitado trecho da oitava Elegia: "Ignoramos o que é contemplar um dia, somente / um dia o espaço puro, onde, sem cessar, / as flores desabrocham."

Porém, o que chama essa consciência? Que representação é essa? Só podemos lê-la no sentido de algo que dá a compreender sem nenhum acontecimento de significado, isto é, como pura Voz - no sentido que lhe emprega Agamben -, como "pura intenção de significar sem nenhum acontecimento concreto de significado, um puro querer-dizer que não diz nada" (AGAMBEN, 2002, p. 96). ${ }^{13}$ Essa Voz chama apenas como puro silêncio - e talvez aqui a insistência rilkeana no estar só, no estar em silêncio. Em Rilke, portanto, a insistência em dizer o próprio interior (em fazer experiência da morte) é sinônimo de um querer dizer que é apenas celebrativo; ou melhor, o que as Elegias fazem é apenas lamentar e ao mesmo tempo o celebrar (a elegia rilkeana é sim um hino) a própria falta de conteúdo do poema (e de toda língua), seu girar no vazio como pura forma de glorificação dos deuses (AGAMBEN, 2007b, p. 260).

A experiência poética de Rilke pode ser lida, portanto, sempre como uma celebração do vazio, diferentemente da explosão mallarmaica do poema - esta que, na figura do Coup de dés, funda a lírica moderna como uma teo-a-logia (Idem, p. 262), abrindo a si mesma uma potência de dizer, um novo uso ininterrupto da língua (nem comunicativo, nem informativo). Em Rilke a poesia capturar o centro oco da máquina que produz a todo instante uma série de cisões: homem/animal, mito/rito, conhecimento/não-conhecimento. Diferentemente de uma postura mística que se assume em um dos pólos - que, justamente como no poema de João da Cruz, "com um não saber sabendo / Irá sempre transcendendo" - o esoterismo rilkeano vê no Aberto, o qual só o animal pode ver, a impossibilidade de uma palavra humana livre (o que faz de seu gesto sempre uma retro-ação em face do coup de Mallarmé). Ou seja, se na modernidade há realmente uma suspensão de toda propriedade humana, ou melhor humanística (de toda propriedade de uma morte, portanto), o próprio ato de linguagem (a palavra) é a exposição de seu núcleo a-semântico; a máquina (antropológica, mitológica, lingüística) permanece insistentemente girando no vazio (ainda que a

13 “(...) pura intención de significar sin ningún acontecimiento concreto de significado, un puro quererdecir que no dice nada." 
máquina capitalista de fim dos tempos em que vivemos demonstre sua hábil capacidade de capturar até mesmo esse vazio: basta pensar na agudeza de qualquer mensagem publicitária, nos programas biopolíticos estatais etc.). Que a intenção rilkeana seja justamente a glorificação desse espaço é flagrante se lermos o início da primeira Elegia:

Quem, se eu gritasse, entre as legiões dos Anjos me ouviria? E mesmo que um deles me tomasse inesperadamente em seu coração, aniquilar-me-ia sua existência demasiado forte. Pois que é o Belo senão o grau do Terrível que ainda suportamos e que admiramos porque, impassível, desdenha destruir-nos? Todo Anjo é terrível.

E eu me contenho, pois, e reprimo o apelo do meu soluço obscuro. Ai, quem nos poderia valer? Nem Anjos, nem homens e o intuitivo animal logo adverte que para nós não há amparo neste mundo definido. Resta-nos, quem sabe, a árvore de alguma colina, que podemos rever cada dia; resta-nos a rua de ontem e o apego cotidiano de algum hábito que se afeiçoou a nós e permaneceu. E a noite, a noite, quando o vento pleno dos espaços do mundo desgasta-nos a face - a quem se furtaria ela, a desejada, ternamente enganosa, sobressalto para o coração solitário? Será mais leve para os que se amam? $\mathrm{Ai}$, apenas ocultam eles, um ao outro, seu destino. Não o sabias? Arroja o vácuo aprisionado em teus braços para os espaços que respiramos - talvez os pássaros sentirão o ar mais dilatado, num vôo mais comovido (RILKE, 2001, pp. 17-19).

Rilke se dá conta donúcleo vazio; tanto é assim que sugere ao jovem poeta Kappus o ensimesmar-se como modo de produção poética (RILKE, 2003, p. 27). É seu mérito ver na abertura do centro vazio - e podemos dizer, inoperante - do humano (das máquinas) a propriedade ínsita à configuração de uma antropogênese. Ao colocar, porém, de modo diverso de Mallarmé (a quem podemos agregar as propostas dos dadaístas), na celebração desse vazio o instante de sua absolvição enquanto sujeito poético, acaba por se deixar capturar por um dispositivo que, invertendo o seu próprio ato de exposição do vazio, coloca-o novamente na posição de eu-poeta; isto é, o seu ingresso naqueles limiares (vida/morte, conhecimento/não-conhecimento, homem/animal), corre o risco de se ver aprisionado e condenado a um além no qual jamais o poeta conseguirá entrar. Tal como numa celebração religiosa, a poesia de Rilke se prostra diante do deus (que nela é apenas vácuo) para celebrá-lo, cantá-lo e glorificálo. Assim, ao anafórico e vazio amém dos fiéis às palavras de louvor dos sacerdotes 
(que é como que a resposta de quem não tem mais nada a dizer), podem ser equiparadas as palavras poéticas das Elegias rilkeanas que, retoricamente, cantam o próprio silêncio do poeta.

\section{REFERÊNCIAS}

ADORNO, Theodor W. Mínima Moralia. Reflexões a partir da vida danificada. São Paulo: Ática, 1992. Tradução: Luiz Eduardo Bicca.

AGAMBEN, Giorgio. El Lenguaje e la Muerte. Un seminario sobre el lugar de la negatividad. Valencia: Pré-Textos, 2002. Traducción de Tomás Segovia.

. Estâncias. A palavra e o fantasma na cultura ocidental. Belo Horizonte: UFMG, 2007. Tradução: Selvino Assmann.

___. Homo Sacer. O Poder Soberano e a vida nua I. Belo Horizonte: UFMG, 2002. Tradução: Henrique Burigo.

__. Il Regno e la Gloria. Per una genealogia teologica dell'economia e del goberno. Homo sacer, II, 2. Vincenza: Neri Pozza Editore, 2007.

. La Puissance de la Pensée. Essais et conférences. Paris: Éditions Payot \& Rivages, 2006. Traduit de l'italien par Joel Gayraud et Martín Rueff.

. Quel Che Resta di Auschwitz. L'archivio e il testimonio. Torino: Bollati Boringhieri, 1998.

BLANCHOT, Maurice. O Espaço Literário. Rio de Janeiro: Rocco, 1987. Tradução: Álvaro Cabral.

CAMPOS, Augusto de. Coisas e anjos de Rilke. São Paulo: Perspectiva, 2007.

JESI, Furio. Artigo publicado em: Il Castoro, n. 54, Giugno 1979, encontrado no sítio: http://worldlibrary.net/eBooks/Wordtheque/it/AAAARS.TXT

. Materiali Mitologici. Mito e antropologia nella cultura mitteleuropea. Torino: Einaudi, 2001.

KANTOROWICZ, Ernst. Os Dois Corpos do Rei. Um estudo sobre teologia política medieval. São Paulo: Companhia das Letras, 1998. Tradução: Cid Knipel Moreira.

RILKE, Rainer M.. Cartas a um Jovem Poeta. A Canção de Amor e de Morte do PortaEstandarte Cristóvão Rilke. São Paulo: Globo, 2003. Tradução: Paulo Rónai e Cecília Meireles.

. Elegias de Duíno. São Paulo: Globo, 2001. Tradução: Dora Ferreira da Silva. 
SÃO JOÃO DA CRUZ. Obras Completas. Petrópolis: Vozes; Carmelo Descalço do Brasil, 1996.

SIMMEL, Georg. La Tragédie de la Culture. Paris: Editions Rivages, 1988. Traduit de 1'allemand par Sabine Cornille et Philippe Ivernel.

TIQQUN. Théorie du Bloom. Paris: La fabrique editions, 2000. 